\title{
Preservación de activos digitales: \\ el seguro digital definitivo
}

\section{Roberto González Siguero}

PIQL SPAIN

DesarRollo DE NeGocio

\section{Resumen}

La gran cantidad de información digital disponible en estos momentos requiere por parte de las instituciones archivísticas una política de preservación a largo plazo que asegure el acceso y uso futuro de los activos digitales. En este trabajo se presenta una solución de preservación digital que aprovecha las virtudes del soporte película para asegurar dicho acceso, del mundo digital para la explotación de los recursos digitales y de un archivo con frío natural para su conservación. Basado en el estándar de preservación OAIS, el sistema permite la gestión integral de los activos a preservar, y asegura el acceso futuro (hasta 500 años) con su tecnología bits on film abierta e independiente de los fabricantes.

Palabras clave: Preservación digital; Microfilm digital; OAIS; Open source; Seguridad de los datos

Cita recomendada: González Siguero, R. (2018). Preservación de activos digitales: el seguro digital definitivo. En El archivo electrónico en la administración digital: 23 Jornadas de Archivos Universitarios, 21-23 de junio de 2017, A Coruña (pp. 121-127).

DOI capítulo: https://doi.org/10.17979/spudc.9788497496803.121

DOI libro: https://doi.org/10.17979/spudc.9788497496803 


\section{Introducción}

En la época actual, en la que se manejan cantidades enormes de información digital, se hace muy difícil conseguir la conservación de esta producción intelectual para que pueda ser utilizada de nuevo en el futuro. Los activos digitales son frágiles (Termens, 2013) y no podemos optar por no hacer nada como en el mundo analógico, almacenarlos en un depósito y esperar que la falta de interacción humana permita recuperarlos en su estado original. En el caso de los datos digitales se necesitan actitudes proactivas para asegurar el acceso futuro.

Además, es necesario asegurar la autenticidad e integridad de los datos, puesto que la facilidad de edición de los mismos puede provocar pérdidas de información, sea de forma consciente, por error, por negligencia o por una acción externa (virus u otros).

Por último, no solo es necesario asegurar el acceso futuro sino también la experiencia y uso actuales. Por ejemplo, de nada sirve almacenar un fichero de texto con formato si en el futuro el usuario no pudiera reproducir los mismos formatos, imágenes, tablas, etc. que contuviera, puesto que dan información adicional que es valiosa para la interpretación.

Este problema no es nuevo y muchas personas implicadas en el mundo digital llevan tiempo avisando de la necesidad de tomar consciencia de la necesidad de la preservación de cualquier tipo de información digital. Uno de ellos es Vint Cerf, vicepresidente de Google, que en sus múltiples conferencias y artículos menciona el peligro de pérdida de información en el que nos encontramos (Sample, 2015).

Por todo esto, la empresa noruega Piql inició en 2007 varios proyectos de investigación para la aplicación de tecnología audiovisual (en concreto película de $35 \mathrm{~mm} \mathrm{~b} / \mathrm{n}$ ) para la preservación de información digital de 
cualquier tipo, aprovechando las buenas características del soporte respecto a varios de los problemas, a saber, longevidad, autenticidad e integridad (Plata y Bjerkestrand, 2012; Drake y Brudeli, 2014).

Este proceso culminó en 2014 con la publicación del informe técnico por parte de Technicolor para confirmar la viabilidad del producto en la conservación de cualquier tipo de información digital y su puesta en el mercado.

\section{Solución de Preservación Piql}

La solución Piql está basada en el uso de una película de poliéster de $35 \mathrm{~mm}$ con emulsión de haluros de plata, en la que se imprime un código de barras 2D que es el encargado de almacenar la información digital. Este código de barras permite la preservación de cualquier tipo de datos digitales, documentos, sonido, vídeo y bases de datos entre otros.

La elección del soporte film se hizo por sus buenas características de longevidad, que han sido probadas por laboratorios independientes, certificando (según normas ISO 18901, 18936 y 18924) la recuperación de la información dentro de 500 años en condiciones normales de temperatura y humedad. Además, es un medio realmente offline que no utiliza energía para la conservación, y es a prueba de piratería puesto que no es modificable (Figura 1).

Para la lectura solamente se requiere una fuente de luz y un sensor capaz de convertir luz en señales digitales, ambos ya están disponibles en el mercado. Piql ofrece una solución incluyendo estos elementos, pero no es necesario que se utilice la tecnología Piql, puesto que los sensores de otros fabricantes son igualmente válidos para la obtención de los fotogramas. Con los fotogramas escaneados y mediante un software de 
fuentes abiertas (que además está escrito en la película) es posible obtener el fichero original que se escribió.

Como puede observarse, requiere de poca tecnología y además es directamente legible por las personas.

Para facilitar la interpretación futura de los datos, la propia película incluye una parte en formato visible, que describe el formato del código de barras, metadatos, el software de decodificación, instrucciones para la decodificación de los datos y cualesquiera otros que faciliten el acceso a alguien que no conozca el contenido. Esta información puede adaptarse a las necesidades del usuario (Figura 2).

Aunque el aspecto más novedoso de la solución Piql es el soporte, el sistema incluye un entorno completo IT (Information Technologies) en el que se facilita la gestión diaria de los activos a preservar. Dispone de un buscador sobre los metadatos definidos y, si el activo está offline, permite realizar su recuperación desde la película. Además, dispone de API (Application Programming Interface) de integración con otros sistemas para la introducción y recuperación de la información. Por último, permite controlar y definir las operaciones previas al envío de la información a la película, como son la normalización de formatos, verificación de los mismos, antivirus, introducción automática de metadatos y otros, para facilitar el día a día a los usuarios.

Otro aspecto importante de la solución es la seguridad de los datos almacenados. El Centro de Investigación de la Defensa de Noruega ha realizado un análisis de la solución Piql frente a las amenazas de la ciberguerra actual, llegando a la conclusión de que es una solución muy interesante para la conservación de información valiosa. Las características fundamentales de la solución en el ámbito de la seguridad son el almacenamiento desconectado, el sistema de archivo automatizado, 
la no necesidad de migración, la longevidad y la confiabilidad de los materiales en los que se basa el archivo (Norwegian Defence Research Establishment, 2016).

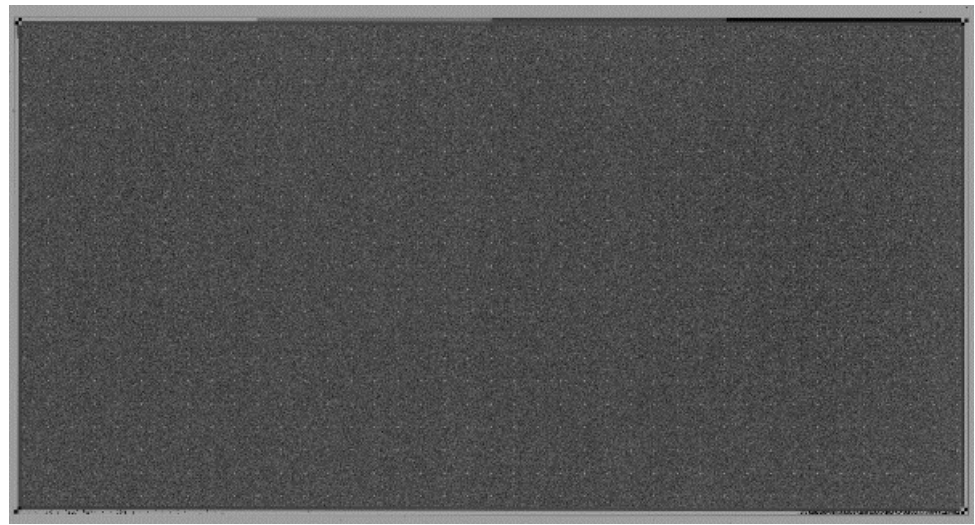

Figura 1. Fotograma en piqlFilm

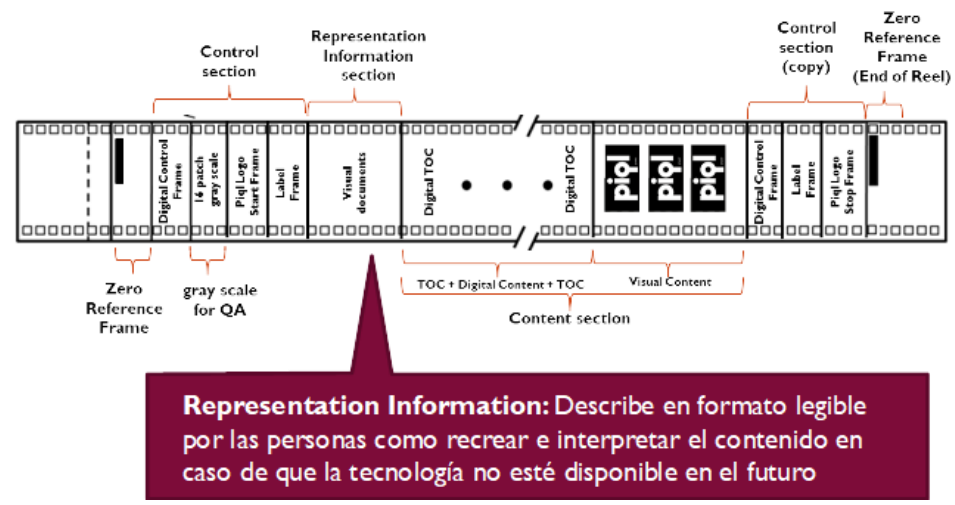

Figura 2. Información de representación 
Por último, como se ha mencionado anteriormente, las condiciones de almacenamiento de la película para su conservación durante 500 años no necesitan ser especiales. No obstante, si la temperatura y humedad del lugar son óptimas, ese tiempo se prolongará. Por ello se ha creado el Archivo Ártico Mundial en las Islas Svalbard para el almacenamiento de las películas en unas condiciones naturales de frío y baja humedad que permitan ampliar el tiempo de conservación, igualmente, se garantiza la seguridad frente a desastres naturales, eventos nucleares y otros sucesos, puesto que se ubica en una mina abandonada a $300 \mathrm{~m}$ por debajo del suelo. Adicionalmente, las Islas Svalbard están protegidas por el Tratado de Spitsbergen de 1920, por el que los firmantes pueden acceder a los recursos de las islas, entre los que se encuentra el archivo.

\section{Conclusiones}

La solución de preservación Piql asegura la autenticidad de la información digital con un medio inalterable, asegura el acceso futuro a través de un formato auto-contenido y tiene una longevidad probada para 500 años en un sistema compatible con el modelo de preservación OAIS. Además, puesto que no requiere intervenciones posteriores para la conservación, constituye un modelo sostenible económicamente en el tiempo y muy respetuoso con el medio ambiente. 


\section{Bibliografía}

Drake, K. M., y Brudeli, B. H. (2014). A holistic approach to digital preservation. Archiving 2014 final program and proceedings, 2014: 79-83.

Norwegian Defence Research Establishment (2016). A risk assessment of the Piql preservation services. Recuperado de <https://www.ffi.no/no/ Rapporter/16-00707.pdf>

Plata, O. y Bjerkestrand, R. (2012). The archivator: a solution for long-term archiving of digital information. Archiving 2012 final program and proceedings, 2012: 70-74.

Sample, I. (2015, Febrero). Google boss warns of 'forgotten century' with email and photos at risk. The Guardian. Entrevista a Vint Cerf. Recuperado de $<$ https://www.theguardian.com/technology/2015/feb/13/google-boss-warnsforgotten-century-email-photos-vint-cerf $>$.

Termens, M. (2013). Preservación digital. Barcelona: Universitat Oberta de Catalunya. 